\title{
Frontoethmoidal encephalocele: a pediatric airway challenge
}

\author{
Lakshmi M. Geddam, MD • Mohamed A. Mahmoud, MD • Brian S. Pan, MD • \\ Charles B. Stevenson, MD • Ali I. Kandil, DO, MPH
}

Received: 30 July 2017/Revised: 9 September 2017/Accepted: 29 September 2017/Published online: 16 October 2017

(C) Canadian Anesthesiologists' Society 2017

A three-month-old male infant with a history of frontoethmoidal encephalocele presented for surgical repair of the lesion. Because of the anatomical location of the encephalocele, difficult mask ventilation was anticipated. Accordingly, meticulous care was taken to ensure adequate seal with a Carefusion infant size 2 face mask (Carefusion Corporation, San Diego, CA, USA) placed over the mouth, just below the lesion, while compressing the nasal alae prior to anesthesia induction. Anesthesia was induced by inhalation of $100 \% \mathrm{O}_{2}$ plus sevoflurane $8 \%$, followed by establishment of intravenous access. Adequate ventilation was confirmed through mask ventilation and again after a size 1 Ambu supraglottic airway (Ambu, Ballerup, Denmark) was inserted. After testing the ability to ventilate the patient with moderate positive pressure via the supraglottic airway, neuromuscular blockade was administered. We proceeded to complete a full airway evaluation. The supraglottic airway was removed, and direct laryngoscopy revealed a grade $2 b$ view. An air- $Q^{\mathrm{TM}}$ (Mercury Medical, Clearwater, FL, USA) supraglottic airway ${ }^{1}$ size 1 was inserted, and easy ventilation was again confirmed. A 3.0 cuffed endotracheal tube subsequently easily passed through the supraglottic airway without the use of flexible bronchoscopy to assist in its passage. Placement was confirmed by capnography. Oxygen desaturation did not occur during airway evaluation or intubation. The patient

L. M. Geddam, MD $(\bowtie) \cdot$ M. A. Mahmoud, MD .

B. S. Pan, MD - C. B. Stevenson, MD - A. I. Kandil, DO, MPH

Cincinnati Children's Hospital Medical Center, Cincinnati, OH,

USA

e-mail: Lmgeddam@gmail.com remained intubated at the end of the procedure and was extubated on postoperative day 2 .

Anterior skull base encephaloceles are rare congenital abnormalities characterized by herniation of intracranial contents through the cranial and facial bones. Patients undergoing surgical repair of these lesions require special consideration for airway management because of anticipated difficult mask ventilation. Our intubation technique is likely to be valuable in this scenario especially when a small pediatric fibreoptic bronchoscope is not available (Figure).

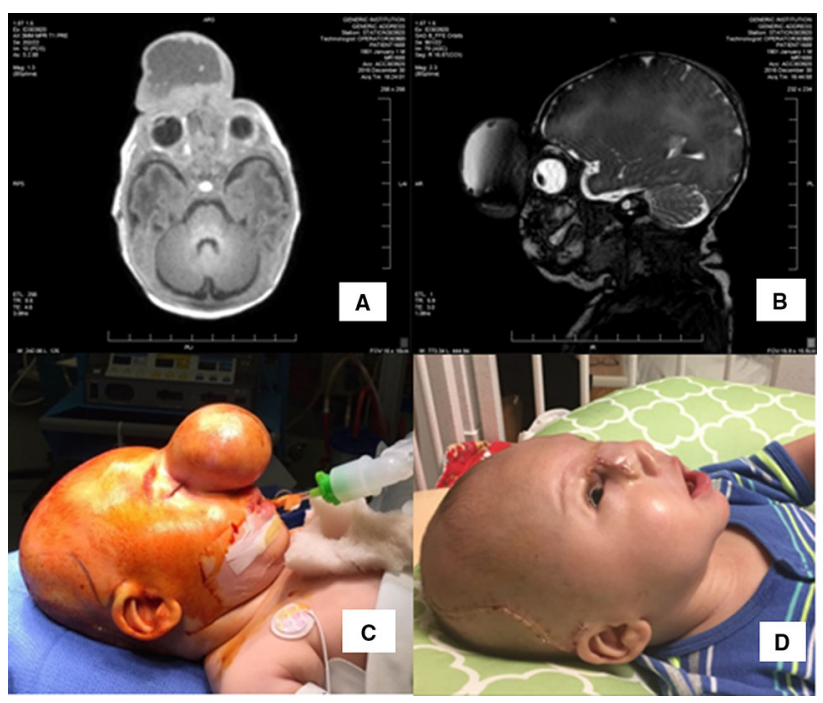

Figure Panels A and B: Axial and sagittal preoperative magnetic resonance images of the brain demonstrating the large skull base encephalocele measuring $4.7 \mathrm{~cm} \times 4.6 \mathrm{~cm} \times 3.9 \mathrm{~cm}$; Panel C: Patient with an established airway, prior to encephalocele resection and craniofacial reconstruction; Panel D: Patient on postoperative day 3 , following extubation 
Conflicts of interest None declared.

Editorial responsibility This submission was handled by Dr. Hilary P. Grocott, Editor-in-Chief, Canadian Journal of Anesthesia.

\section{Reference}

1. Jagannathan $N$, Sohn L, Ramsey $M$, et al. A randomized comparison between i-gel ${ }^{\mathrm{TM}}$ and the air- $\mathrm{Q}^{\mathrm{TM}}$ supraglottic airways when used by anesthesiology trainees as conduits for tracheal intubation in children. Can J Anesth 2015; 62: 587-94. 